\title{
Erratum to: Metabolic profiling of mulberry (Morus alba) wine fermented using Saccharomyces cerevisiae JIS strain
}

\author{
Man Saeng Jang ${ }^{1,2}$, Geo Lyong Lee ${ }^{2 *}$ \\ ${ }^{1}$ Agricultural Corporation Chojeong Co., Ltd, Gokseong 57505, Korea \\ ${ }^{2}$ Department of Integrative Medicine, Sunmoon University, Asan 31460, Korea
}

\section{Erratum to: Saccharomyces cerevisiae JIS 균주로 발효한 오디와인의 대사체 분석}

\author{
장만생 ${ }^{1,2} \cdot$ 이거룡 ${ }^{2 *}$ \\ 1농업법인회사 (주)초정, ${ }^{2}$ 선문대학교 통합의학과
}

한국식품저장유통학회지 27권 2호(2020년 4월 30일 발행), p 232-241에 게재된 Man Saeng Jang, Geo Lyong Lee 저자의 "Metabolic profiling of mulberry (Morus alba) wine fermented using Saccharomyces cerevisiae JIS strain" 논문을 정정합니다. 교신저자 아닌 저자에게 교신저자 표시가 되어 아래와 같이 정정하며, 독자들께 오류로 인해 혼란을 드린 점 사과드립니다.

\section{After correction}

\author{
Man Saeng Jang ${ }^{1,2}$, Geo Lyong Lee ${ }^{2 *}$ \\ ${ }^{1}$ Agricultural Corporation Chojeong Co., Ltd, Gokseong 57505, Korea \\ ${ }^{2}$ Department of Integrative Medicine, Sunmoon University, Asan 31460, Korea \\ 장만생 $1,2 \cdot$ 이거룡 ${ }^{2 *}$ \\ ${ }^{1}$ 농업법인회사 (주)초정, ${ }^{2}$ 선문대학교 통합의학과
}

\section{References}

Jang MS, Lee GL. Metabolic profiling of mulberry (Morus alba) wine fermented using Saccharomyces cerevisiae JIS strain.

Korean J. Food Preserv, 27, 232-241 (2020)

\footnotetext{
*Corresponding author. Geo Lyong Lee. E-mail : leeashram@hanmail.net, Phone : +82-41-530-2604, Fax : +82-41-530-2968 Copyright (c) The Korean Society of Food Preservation.

This is an Open Access article distributed under the terms of the Creative Commons Attribution Non-Commercial License (http://creativecommons.org/licenses/by-nc/4.0) which permits unrestricted non-commercial use, distribution, and reproduction in any medium, provided the original work is properly cited.
} 